\title{
PISONIA DONNELLSMITHII (NYCTAGINACEAE), ADICIÓN A LA FLORA DE GUERRERO, MÉXICO
}

\author{
César Adrián GonzÁlez-MartíneZ ${ }^{1,2}$ y Ramiro Cruz Durán ${ }^{1}$ \\ ${ }^{1}$ Universidad Nacional Autónoma de México, Facultad de Ciencias, Departamento \\ de Biología Comparada, Apdo. postal 70-181, Delegación Coyoacán, 04510 \\ México, D.F., México. \\ ${ }^{2}$ Autor para la correspondencia: cagonzalez_m@outlook.com
}

\section{RESUMEN}

Se presenta la adición de Pisonia donnellsmithii Heimerl ex Standl. (Nyctaginaceae) a la flora del estado de Guerrero, México. Se pueden por primera vez describir las flores femeninas, los frutos y las semillas. Adicionalmente, se presenta la descripción del género, una ilustración de este taxon y una clave para las especies de Pisonia en México.

Palabras clave: Florística, nuevo registro, taxonomía.

\section{ABSTRACT}

The addition of Pisonia donnellsmithii Heimerl ex Standl. (Nyctaginaceae) to the flora of Guerrero state, Mexico, is presented. For the first time, it is possible to describe the pistillate flowers, the fruits, and the seeds. The description of the genus, an illustration of this taxon, as well as a key to the species of Pisonia in Mexico are also included.

Key words: Floristics, new record, taxonomy.

El género Pisonia L. (Nyctaginaceae) contiene alrededor de 40 especies (Spellenberg, 2001), con distribución pantropical (Spellenberg, 2003) en regiones tropicales y subtropicales, principalmente en América y sureste de Asia de donde es nativo (Spellenberg, 2001; Hernández y Flores, 2003). Está representado en México por cinco especies, tres de ellas endémicas (León de la Luz y Levin, 2012): Pisonia 
flavescens Standl., P. capitata (S. Watson) Standl. y P. calafia León de la Luz et Levin. El género se caracteriza por presentar tallos generalmente con espinas axilares, flores unisexuales, flores estaminadas con perianto campanulado, estambres exsertos y antocarpos coriáceos, con cinco costillas longitudinales cubiertas por glándulas víscidas y estipitadas (Fay, 1980).

En el tratamiento de Nyctaginaceae de la Flora de Guerrero, Zavala y Fonseca (2014) registran únicamente la presencia de Pisonia aculeata L. Sin embargo, en las exploraciones botánicas realizadas en este estado durante 2014 y 2015, particularmente en el ejido de Acahuizotla, se recolectó $P$. donnellsmithii Heimerl ex Standl. con inflorescencias estaminadas, pistiladas e infructescencias. Esta especie ha sido reportada en México solo en los estados de Chiapas y Oaxaca (Breedlove, 1986; García-Mendoza y Meave, 2011). Cabe mencionar que anteriormente se citó la presencia de P. capitata (S. Wats.) Standl. en Guerrero (Pérez et al., 2000), pero al revisar el material depositado en los herbarios FCME y MEXU, donde se dispone del mayor número de especímenes recolectados para la Flora de Guerrero, no se encontraron ejemplares provenientes de dicha entidad.

Por ello, a continuación se presenta la descripción de Pisonia (modificada en parte de Zavala y Fonseca, 2014), y de P. donnellsmithii, ya que solo se habían descrito las inflorescencias estaminadas (Standley, 1911; Standley y Steyermark, 1946), basada en los ejemplares de Guerrero depositados en FCME; así como una clave para distinguir entre las especies de este género presentes en México.

Pisonia L. Sp. Pl. 2: 1026. 1753.

Ceodes J.R. Forst. \& G. Forst., Char. Gen. Pl. 71. 1775.

Calpidia Thouars., Hist. Veg. Isles Austral. Afriq. 37, t. 10. 1805. Especie tipo: Pisonia aculeata L.

Árboles, arbustos o bejucos leñosos, dioicos. Tallos erectos o escandentes; ramificación dicotómica opuesta o subopuesta, con entrenudos desiguales; espinas presentes o ausentes, axilares. Hojas simples, opuestas o subopuestas, pecioladas; láminas coriáceas, glabras o pubescentes, con margen entero. Inflorescencias en cimas paniculadas, capituliformes, umbeliformes, coriformes o tirsiformes, axilares o terminales; pedúnculo glabro, puberulento o cortamente viloso. Flores sésiles o pediceladas, con 1 a 3 bractéolas; pedicelos puberulentos o cortamente vilosos o víscidos. Flores estaminadas con perianto campanulado, en ocasiones costillado externamente, con glándulas papilosas víscidas; estambres 5 a 10(40), filamentos filiformes, desiguales, exsertos o incluidos; pistilodio con ovario reducido y estéril. 
Flores pistiladas con perianto constreñido por debajo de los lóbulos; ovario sésil o estipitado; estilo filiforme, cortamente exserto; estaminodios alrededor del ovario, con anteras reducidas. Frutos antocarpos oblongos o elipsoides, coriáceos, glabros, pubescentes o tomentulosos, lisos o con 5-10 costillas con numerosas glándulas víscidas, estipitadas o papilosas. Semillas con testa hialina adherida al pericarpo.

\section{CLAVE PARA LAS ESPECIES DE PISONIA EN MÉXICO}

1 Plantas inermes o rara vez con espinas.

2 Plantas inermes; perianto de las flores estaminadas estrechamente campanulado; antocarpos con 10 costillas provistas de glándulas papilosas víscidas; Chiapas, Guerrero y Oaxaca P. donnellsmithii

2 Plantas generalmente inermes o con espinas rectas de 5 a $6 \mathrm{~mm}$ de largo; perianto de las flores estaminadas ampliamente campanulado; antocarpos con 5 costillas provistas de inconspicuas glándulas estipitadas; Baja California Sur P. flavescens

1 Plantas con espinas.

3 Antocarpos desprovistos de glándulas en la madurez; Baja California Sur P. calafia

3 Antocarpos provistos de glándulas en la madurez.

4 Ramas rojizas; perianto de las flores estaminadas blanco-verdoso; vertiente del Pacífico, Centro y Sur de México P. aculeata

4 Ramas grisáceas o amarillentas; perianto de las flores estaminadas rojo oscuro; Chiapas, Michoacán, Sinaloa y Sonora P. capitata

Pisonia donnellsmithii Heimerl ex Standl. Contr. U.S. Natl. Herb. 13(11): 387. 1911. Tipo: GUATEMALA. Department of Amatitlan, Los Verdes, Heyde y Luz 6301 (US!).

Arbustos, hasta de $4 \mathrm{~m}$ de alto, densamente frondosos, inermes; dioicos; tallos de color pardo claro o amarillentos, efusos; corteza dura, lisa; ramas jóvenes estriadas longitudinalmente, puberulentas, con tricomas curvos amarillentos a rojizos, tempranamente glabras. Hojas usualmente surgen en ramas cortas laterales, o hasta 5 por nudo, subopuestas, aparentando ser alternas, el haz de color verde oscuro, el envés verde claro; pecíolos de (0.7)1.1 a 9.8(12.5) mm de largo, aplanados dorsalmente, vilosos, con tricomas curvados, de color blanco-amarillento, mayormente 
distribuidos en la cara dorsal; láminas elípticas, ocasionalmente orbicular-elípticas, 0.7 a $8.2 \mathrm{~cm}$ de largo, 0.5 a $3 \mathrm{~cm}$ de ancho, ápice acuminado, rara vez agudo, base atenuada o cuneada, decurrente, margen revoluto-ondulado, haz y envés con la vena media vilosa o puberulenta en la base, glabrescente hacia el ápice, con tricomas hialinos, septados. Inflorescencias estaminadas en cimas capituliformes, compactas, terminales, ocasionalmente axilares, de 1.2 a $1.4 \mathrm{~cm}$ de largo, 0.8 a $0.9 \mathrm{~cm}$ de ancho; pedúnculos de 0.5 a $0.9 \mathrm{~cm}$ de largo, verdes a rojizos, vilosos, sostenidos por 4 a 6 brácteas, triangular-ovadas, 0.7 a $1.3 \mathrm{~mm}$ de largo, ápice agudo, densamente viloso; pedicelos de 0.4 a $1.2 \mathrm{~mm}$ de largo, ligeramente vilosos, con 1 a 3 bractéolas, persistentes, triangular-ovadas o cimbiformes, 0.7 a $1 \mathrm{~mm}$ de largo, 0.3 a $0.7 \mathrm{~mm}$ de ancho, carnosas, ápice ligeramente agudo o redondeado, base cuneado-truncada, glabras o ligeramente ciliadas. Flores estaminadas con perianto estrechamente campanulado, 1.9 a $2.8 \mathrm{~mm}$ de largo, 1.2 a $1.7 \mathrm{~mm}$ de ancho, de color verde-amarillento, cortamente puberulento, con glándulas papilosas víscidas diminutas, de color blanco, en las costillas, con 5 lóbulos triangular-obtusos, 0.6 a $0.8 \mathrm{~mm}$ de largo, 1 a $1.3 \mathrm{~mm}$ de ancho, con concrescencias en los pliegues, externamente; estambres (6)7(8), filamentos subiguales, 3 a $4.7 \mathrm{~mm}$ de largo; pistilo rudimentario, globoso o ligeramente cónico, 0.7 a $1.3 \mathrm{~mm}$ de largo. Inflorescencias pistiladas en cimas capituliformes, compactas, terminales, ocasionalmente axilares de 2.4 a $4.7 \mathrm{~cm}$ de largo, 1.5 a $3.1 \mathrm{~cm}$ de ancho; pedúnculos de 1.4 a $3 \mathrm{~cm}$ de largo, de color verde, ligeramente puberulentos, con $1 \mathrm{o}$ 2 brácteas subyacentes, triangular-ovadas, 0.7 a $1.3 \mathrm{~mm}$ de largo, ápice agudo, densamente viloso; con pedicelos de 0.9 a $2.3(7.8) \mathrm{mm}$ de largo, acrescentes en el fruto, de 1.9 a $4.5 \mathrm{~cm}$ de largo, con 1 a 3 bractéolas, persistentes, triangular-ovadas o cimbiformes, 0.7 a $1 \mathrm{~mm}$ de largo, 0.3 a $0.7 \mathrm{~mm}$ de ancho, carnosas, ápice ligeramente agudo o redondeado, base cuneado-truncada, glabras o ligeramente ciliadas. Flores pistiladas con perianto tubular-urceolado, constreñido por debajo de los lóbulos, 2.8 a $4.2 \mathrm{~mm}$ de largo, 1.2 a $1.8 \mathrm{~mm}$ de ancho, de color verde-amarillento, glabrescente a esparcidamente puberulenta, con glándulas papilosas víscidas evidentes, de color anaranjado, en 1 hilera en cada uno de las 10 costillas, tricomas septados, blancoamarillentos, con 5 lóbulos angostamente triangulares de 0.3 a $0.5 \mathrm{~mm}$ de largo, 0.7 a $0.8 \mathrm{~mm}$ de ancho, con concrescencias en los pliegues; sin estaminodios; ovario sésil, fusiforme, ca. $3 \mathrm{~mm}$ de largo en antesis, estilo $1.2 \mathrm{~mm}$ de largo. Infructescencia con pedúnculo de 3.1 a $6.6 \mathrm{~cm}$ de largo, de color verde a pardo, glabrescentes con exudado depositado. Antocarpos de color verde olivo a pardo, simétricos, elipsoidales, 1.3 a $1.5 \mathrm{~cm}$ de largo, 3 a $4 \mathrm{~mm}$ de ancho, ápice truncado con los lóbulos del perianto persistentes, base atenuada, glabrescente a esparcidamente puberulento, con glándulas papilosas víscidas, de color ámbar, en 1 hilera sobre cada una de las 


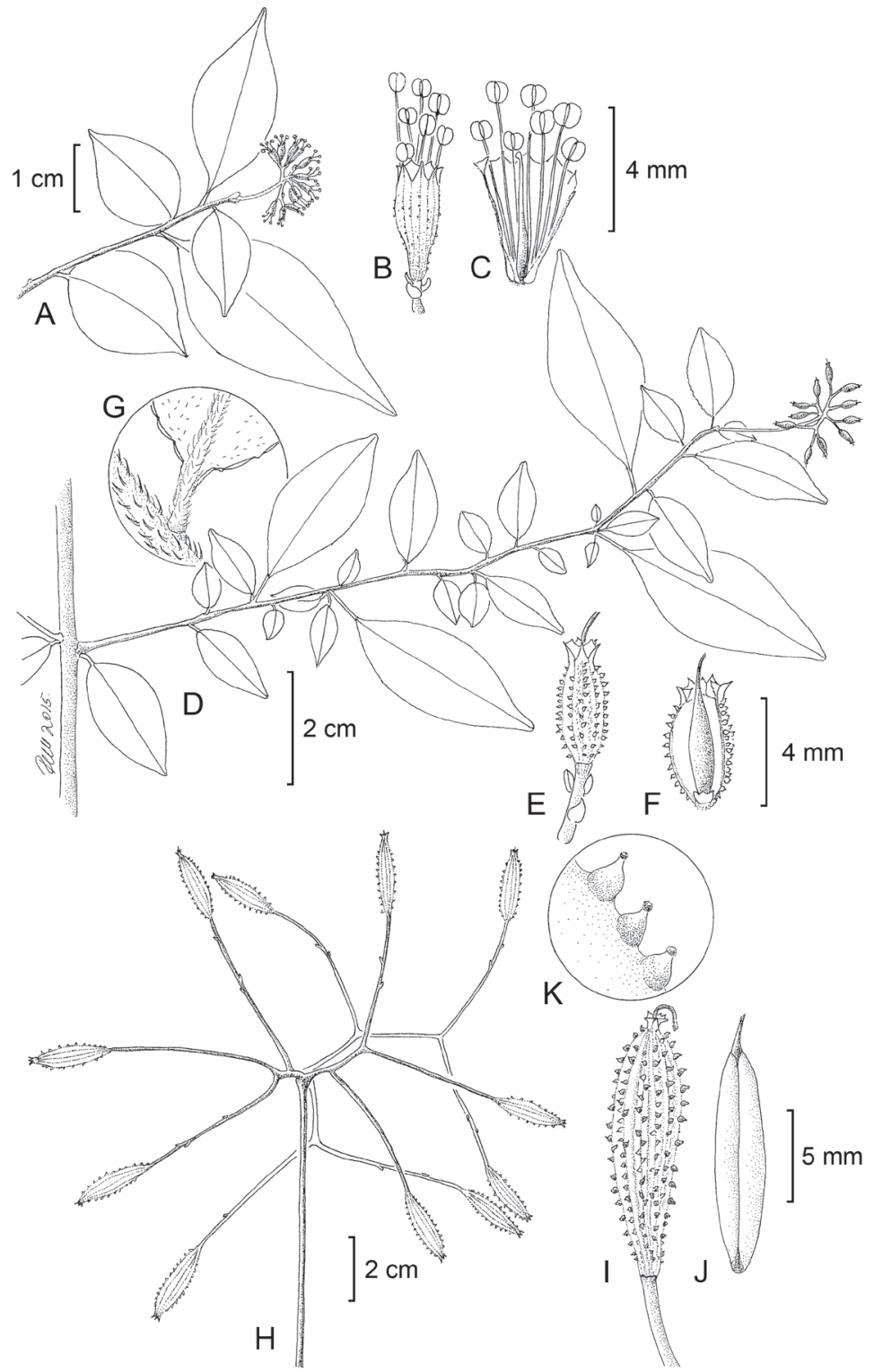

Fig. 1. Pisonia donnellsmithii Heimerl ex Standl. A. rama con inflorescencia estaminada; B. flor estaminada; C. flor estaminada, disección; D. rama con inflorescencia pistilada; E. flor pistilada; F. flor pistilada, disección; G. base de la hoja; H. infructescencia; I. fruto; J. semilla, vista ventral; K. glándulas del fruto. (A-C dibujado de C. A. González-Martínez y S. Rios-Carrasco 935 (FCME); D-G de C. A. González-Martínez y S. Rios-Carrasco 476 (FCME); H-K de C. A. González-Martínez y S. Rios-Carrasco 586 (FCME). Ilustración de Ramiro Cruz Durán. 
10 costillas, pedicelos 2 a $4.3 \mathrm{~cm}$ de largo, conservando las bractéolas. Semillas de color pardo claro-hialino, oblongas, superficie pustulada, $1 \mathrm{a} 1.1 \mathrm{~cm}$ de largo, $3.5 \mathrm{a}$ $3.6 \mathrm{~mm}$ de ancho, con una hendidura longitudinal prominente (Fig. 1).

Distribución: México (Chiapas, Guerrero, Oaxaca), Guatemala y El Salvador.

Ejemplares examinados: Guerrero: Mpio. Mochitlán: Acahuizotla, cerca del río Escondido, pasando la estación de bombeo, 29 mar. 2015 (flor estaminada), $C$. A. González-Martínez y S. Rios-Carrasco 935 (FCME), 29 ago. 2014 (flor pistilada), C. A. González-Martínez y S. Rios-Carrasco 476 (FCME), 26 sep. 2014 (fruto), C. A. González-Martínez y S. Rios-Carrasco 586 (FCME).

Altitud: 780 a $820 \mathrm{~m}$.

Tipo de vegetación: selva mediana subcaducifolia y bosque de galería.

Fenología: florece de marzo a agosto y fructifica en septiembre.

Pisonia donnellsmithii se diferencia de las demás especies de Pisonia por carecer generalmente de espinas, poseer flores estaminadas estrechamente campanuladas y antocarpo con diez costillas, cubiertas por glándulas papilosas víscidas en una hilera, no estipitadas. El taxon presenta cierta variación morfológica: los ejemplares recolectados en Guerrero, México, difieren de los de Guatemala (Standley, 1911), en el tamaño de las láminas foliares $(0.7$ a $8.2 \mathrm{~cm}$ de largo vs. 3 a $5.5 \mathrm{~cm}$ de largo), en los pedúnculos de las inflorescencias estaminadas $(0.5$ a $0.9 \mathrm{~cm}$ de largo vs. $2.2 \mathrm{a} 3 \mathrm{~cm}$ de largo) y en el perianto de las flores estaminadas (1.9 a $2.8 \mathrm{~mm}$ de largo vs. $5 \mathrm{~mm}$ de largo). Asimismo se ha reportado la presencia de espinas cortas y rectas en ejemplares de Guatemala (Standley y Steyermark, 1946), en los de Oaxaca, México (Nava-Zafra 233 con Sánchez y Salas (MEXU)) y de El Salvador (Rosales 1433 (MEXU)). En este último registro se señala que el perianto de las flores estaminadas es blanco, lo que puede deberse a un dato erróneo del colector, o bien, a variación de la especie.

Por último, es importante resaltar que al conocerse las flores femeninas, los frutos y semillas de $P$. donnellsmithii, queda claro que el perianto femenino puede presentar también diez costillas longitudinales, cubiertas por glándulas papilosas víscidas, no estipitadas. Por tanto, la descripción del género ha sido modificada, pues para éste solo se había mencionado la presencia de cinco cos- 
tillas, con glándulas estipitadas (Standley, 1911; Standley y Steyermark, 1946; Fay, 1980; Pérez et al., 2000; Spellenberg, 2001, 2003; Hernández y Flores, 2003; Zavala y Fonseca, 2014).

\section{AGRADECIMIENTOS}

A la Biól. Sandra Rios Carrasco, por su invaluable apoyo en la recolecta de ejemplares en campo, a dos revisores anónimos que hicieron observaciones fundamentales para mejorar el manuscrito, al Dr. Jaime Jiménez Ramírez, por la atención prestada y la revisión crítica del primer manuscrito, a los pobladores de Acahuizotla, Guerrero, por facilitarnos el trabajo en el ejido, al Biól. Antonio Hernández Gómez, Laboratorio de Microcine, Facultad de Ciencias de la UNAM, por la digitalización de la imagen, y a la Dirección General de Asuntos del Personal Académico de la Universidad Nacional Autónoma de México, por el soporte económico a través del Programa de Apoyo a Proyectos de Investigación e Innovación Tecnológica (proyecto IN214112).

\section{LITERATURA CITADA}

Breedlove, D. E. 1986. Listados florísticos de México. IV. Flora de Chiapas. Instituto de Biología, Universidad Nacional Autónoma de México. México, D.F., México. 246 pp. Fay, J. J. 1980. Nyctaginaceae. Flora de Veracruz 13: 1-54.

García-Mendoza, A. J. y J. A. Meave. 2011. Diversidad florística de Oaxaca: de musgos a angiospermas (colecciones y lista de especies). Universidad Nacional Autónoma de México - Comisión Nacional para el Conocimiento y Uso de la Biodiversidad. México, D.F., México. 352 pp.

Hernández, P. y H. Flores. 2003. Nyctaginaceae de Hidalgo, México (parte B). Anales del Instituto de Biología, Universidad Nacional Autónoma de México, serie Botánica 74(2): 231-287.

León de la Luz, J. L. y R. A. Levin. 2012. Pisonia calafia (Nyctaginaceae) species nova from the Baja California Peninsula, México. Acta Botanica Mexicana 101: 83-93.

Pérez, L. A., R. Fernández y M. L. Arreguín. 2000. La familia Nyctaginaceae en la Cuenca del Río Balsas, México. Polibotánica 11: 49-109.

Spellenberg, R. 2001. Nyctaginaceae. Flora del Bajío y de Regiones Adyacentes 93: 1-98.

Spellenberg, R. 2003. Nyctaginaceae. In: Flora of North America. Editorial Committee, Flora of North America Vol. 4: 14-74. Oxford University Press. New York, USA. http://www.efloras.org/florataxon.aspx?flora_id=1\&taxon_id=125604 Consultado: 11 mayo 2015. 
Standley, P. C. 1911. The Allioniaceae of Mexico and Central America. Contributions from the U.S. National Herbarium 13(11): 377-430.

Standley, P. C. y J. A. Steyermark. 1946. Nyctaginaceae. In: Standley, P. C. y J. A. Steyermark (eds.). Flora of Guatemala. Fieldiana Botany 24(4): 174-192

Zavala, S. y R. M. Fonseca. 2014. Nyctaginaceae. Flora de Guerrero 63: 14-86.

Recibido en mayo de 2015.

Aceptado en mayo de 2016. 